\title{
SHEAR BOND STRENGTH OF BISPHENOL A-GLYCIDYL METHACRYLATE ADHESIVE RESIN AFTER APPLICATION OF EUCALYPTUS OIL BEFORE DEBONDING METALLIC ORTHODONTIC BRACKET
}

\author{
ARISTY RIYANTI*, ERWIN SIREGAR, HARU SETYO ANGGANI
}

Department of Orthodontics, Faculty of Dentistry, Universitas Indonesia, Jakarta, 10430, Indonesia. Email: aristyriyanti@gmail.com Received: 10 July 2018, Revised and Accepted: 18 October 2018

\section{ABSTRACT}

Objective: Debonding of orthodontic braces could lead to enamel fracture and moderate discomfort for the patients. This study was conducted to examine whether eucalyptus oil and eucalyptol were effective in decreasing the shear bond strength and facilitate the debonding of metallic brackets bonded with bisphenol A-glycidyl methacrylate (bis-GMA) adhesive resin.

Methods: Thirty upper premolar teeth were randomly divided into the following three groups: Group 1 (75\% eucalyptus oil), Group 2 (100\% eucalyptol), and Group 3 (aquades; controls). Gemini brackets (3M Unitek, Monrovia) were bonded to the teeth using Transbond XT (3M Unitek, Monrovia). The areas around the brackets were lubricated with 75\% eucalyptus oil, 100\% eucalyptol, and aquades for 10 min before debonding.

Results: A significant difference in shear bond strength between Group 2 and the control group was noted $(\mathrm{p}<0.05)$.

Conclusion: The findings of this study indicated that eucalyptol can decrease the shear bond strength of bis-GMA-based adhesive resin after 10 min of application.

Keywords: Bisphenol A-glycidyl methacrylate adhesive resin, Eucalyptus oil, Eucalyptol, Shear bond strength.

(C) 2019 The Authors. Published by Innovare Academic Sciences Pvt Ltd. This is an open access article under the CC BY license (http://creativecommons. org/licenses/by/4. 0/) DOI: http://dx.doi.org/10.22159/ijap.2019.v11s1.16905

\section{INTRODUCTION}

Several studies have been conducted in an attempt to increase the bonding strength of orthodontic appliances to prevent failure during treatment. Enamel conditioning and the usage of adhesive materials and bracket mesh ensure the effectiveness of the bonding system. However, superior bonding forces may lead to problems during debonding at the end of orthodontic treatment. The visual analog scale, used to assess discomfort, has demonstrated moderate levels of pain (4.6-6.6, where $0=\mathrm{a}$ lot of pain, $5=$ moderate pain, and $10=$ painless) when metallic brackets were removed using pliers [1]. An increase in shear bond strength leads to an increase in the risk of enamel fracture during debonding. In a laboratory setting, enamel fractures were observed on a specimen when the shear bond strength exceeded $13.5 \mathrm{MPa}$ [2]. In another study, an increase in shear bond strength was achieved using Transbond XT adhesive [3].

Several methods had been proposed to reduce force during the debonding of orthodontic brackets to eliminate pain and discomfort for the patients. Mechanical (ultrasonic scaler) and thermal (electrothermal or laser) methods have been proposed to decrease the shear bond strength $[4,5]$. Electrothermal debonding was shown to decrease the shear bond strength by $50 \%$ but was accompanied by some disadvantages such as an increase in temperature within the pulp chamber and the risk of pulp irritation [4]. On the other hand, laser treatments were not economically viable [5]. Ultrasonic scalers might decrease the shear bond strength, but the process can cause discomfort to the patient [6]. Alternatively, the use of organic solvents such as $70 \%$ acetone [7], 90\% ethanol [7], peppermint oil [7], and eucalyptus oil [8] has been proposed to decrease the shear bond strength of orthodontic adhesive [8].

Eucalyptus oil decreased the shear bond strength of a 4-methacryloxyethyl trimellitate anhydride/ methacrylate-tri-n-butyl borane (4-META/MMA-TBB) adhesive after 10 min application [8]. However, the ability of eucalyptus oil to decrease the shear bond strength of other resin-based materials is uncertain; moreover, the optimal concentration required for the purpose remains unknown. In the present study, we examined the ability of $75 \%$ eucalyptus oil and $100 \%$ eucalyptol to decrease the shear bond strength and facilitate the debonding of metallic brackets bonded with bisphenol A-glycidyl methacrylate (bis-GMA) adhesive resin.

\section{METHODS}

\section{Samples}

The study sample consisted of 30 maxillary first or second premolars removed for orthodontic purposes within 6 months before the start of the study. The selected teeth were intact, without any defects on the enamel surface, and had never been in contact with etching gel, sodium hypochlorite, alcohol, or hydrogen peroxide.

\section{Specimen preparation}

The teeth were carefully embedded in self-curing acrylic using molds to orient the buccal surface parallel with the tip of the testing machine. After cleaning with non-fluoride pumice paste, the teeth were etched using $37 \%$ phosphoric acid for 30 s. Premolar brackets (Gemini; 3M Unitek, Monrovia, USA) were bonded to all the teeth using Transbond XT (3M Unitek, Monrovia, USA) adhesive resin and light cured for $20 \mathrm{~s}$ from the mesial and distal aspects. The mean surface area of the bracket was $10.61 \mathrm{~mm}^{2}$. The brackets were positioned $4 \mathrm{~mm}$ away from the occlusal tip and parallel to the base of the tooth specimen. Subsequently, the specimens were immersed in distilled water and incubated at $37^{\circ} \mathrm{C}$ for $24 \mathrm{~h}$.

The specimens were divided into three groups based on the liquids, and they were treated with Group 1,75\% eucalyptus oil (Naga Mas, Buru Island, Indonesia), Group 2, 100\% eucalyptol (Cerkamed, Poland), and Group 3 (control), aquades. The three liquids were placed in uniform dark glass bottles, and a number was assigned to each one to mask the information. 
Experimental procedure

After $24 \mathrm{~h}$, the specimens were randomly divided into three groups of 10 each, and a number was assigned to each specimen. Each specimen was treated with one of the liquids using a microbrush and applied it around the brackets for $10 \mathrm{~min}$. The applications were performed thrice with 3 min intervals. The shear bond test was carried out using Shimadzu AG-5000 universal testing machine (Shimadzu Corporation, Kyoto, Japan) at a crosshead speed of $0.5 \mathrm{~mm} / \mathrm{min}$ and a load of $50 \mathrm{kgF}$. The debonding forces (kgF) were recorded and converted to MPa by dividing the measured force values in Newton by the mean surface area of the premolar bracket.

\section{Data analysis}

Descriptive statistics including mean, standard deviation, and maximum and minimum values were calculated for the three groups tested. Data were assessed using Shapiro-Wilks normality test. Statistical significance between groups was assessed using bivariate one-way analysis of variance and Tukey's post hoc tests. All data were analyzed using SPSS version 17.0 (Chicago, USA), and the significance level was set at $\mathrm{p}<0.05$.

\section{RESULTS}

Table 1 shows the descriptive statistics of the three groups studied. Group 1 (controls) presented with the highest mean strength $(15.50 \pm 3.04 \mathrm{MPa})$ followed by Group $2(14.60 \pm 2.16 \mathrm{MPa})$. The lowest mean bond strength was exhibited by Group 3 (12.42 $\pm 1.95 \mathrm{MPa})$. Significant differences in mean shear bond strengths were noted among the three groups $(\mathrm{p}=0.025)$. Group 3 presented with significantly lower mean bond strengths when compared with Group $3(\mathrm{p}=0.023)$ but not Group $2(\mathrm{p}=0.132)$. No significant difference was found between Groups 2 and $3(\mathrm{p}=0.687)$.

\section{DISCUSSION}

This study aimed to examine the influence of $75 \%$ eucalyptus oil and $100 \%$ eucalyptol on the shear bond strengths of metallic brackets bonded with bis-GMA adhesive resin. A steady decrease in shear strengths in both treatment groups was noted when compared with the control group; furthermore, a significant difference was observed between Group 3 (100\% eucalyptol) and the control group ( $\mathrm{p}<0.05)$. The results of the present study proved that the shear bond strength of bis-GMA adhesive resin can be significantly decreased after application of $100 \%$ eucalyptol to the edges of brackets. These findings are similar to those reported by Yu et al., where the shear bond strength of 4-META/ MMA-TBB adhesive was significantly decreased after immersion in eucalyptus oil for $10 \mathrm{~min}$ [8].

Adhesive materials are classified as polymers and have several properties such as deformation-recovery, rheometry, thermal, and solubility-dissolution properties. Hence, adhesive resins are also called as polymeric materials. Solubility is the ability of a polymer to dissolve in a solvent. The solubility of a polymer is influenced by its solubility parameter from both the solvent and the polymeric material, duration of immersion, temperature, and the crosslink nature of the resin matrix and the filler $[9,10]$. Resin dissolution occurs when the resin gets in contact with the solvents that present a close solubility parameters [11]. The solubility parameters of bis-GMA and triethylene

Table 1: Descriptive statistics of the shear bond strength (MPa) obtained for the experimental groups

\begin{tabular}{lllll}
\hline Groups & \multirow{2}{*}{} & Mean \pm SD & \multicolumn{2}{l}{$\mathbf{9 5 \%}$ confidence interval } \\
\cline { 3 - 5 } & & & Minimum & Maximum \\
\hline Group 1 & 10 & $14.60 \pm 2.16$ & 13.05 & 16.14 \\
Group 2 & 10 & $12.42 \pm 1.95^{*}$ & 11.03 & 13.82 \\
Group 3 & 10 & $15.50 \pm 3.04^{*}$ & 13.32 & 17.68 \\
\hline
\end{tabular}

$\mathrm{N}$ : Number of specimens; ${ }^{*} \mathrm{p}<0.05$ statistically significant difference.

SD: Standard deviation glycol dimethacrylate are 18.6 and $20.5 \mathrm{MPa}^{1 / 2}$, respectively [12]. The Hildebrand solubility parameter for eucalyptol was estimated to be 17.6 $\mathrm{MPa}^{1 / 2}$, and it is capable of dissolving polymers with solubility parameters ranging between 15.5 and $21 \mathrm{MPa}^{1 / 2}$ [13]. Taken together, these findings suggest that the resin in the current study may have been dissolved following the application of $100 \%$ eucalyptol.

No significant difference in mean shear bond strength was noted between Group 1 (75\% eucalyptus oil) and the control group ( $p>0.05)$. The steady decline in bis-GMA shear strength might be related to the composition of the eucalyptus oil, a natural oil containing a mixture of $75 \%$ eucalyptol along with thousands of other compounds, such as pinene, limonene, terpene, cymene, and phellandrene, which accounted for the remaining $25 \%$ [14]. There are $25 \%$ other diverse components that can alter the solubility parameters of eucalyptus oil. The solubility parameter of a solution comprising more than one mixture is calculated on the basis of the volume contribution [15]. However, to the best of our knowledge, the solubility parameter of eucalyptus oil has not been reported so far. This may be due to the changes in the components of eucalyptus oil, which occur due to differences in weather, location, harvesting methods, and the parts from which the oil was extracted [14]. Therefore, it was concluded that eucalyptus oil may not be effective in decreasing the shear bond strength of bis-GMA adhesive resin.

Statistical significance notwithstanding, the decrease in shear bond strength was more marked in Group 2 when compared with Group 1 $(p>0.05)$. This may be due to the higher concentration of eucalyptol in Group 2. Further studies comparing the effects of different concentrations of eucalyptol on the shear bond strengths of orthodontic adhesive resins are warranted.

A $20 \%$ reduction in the shear strength of bis-GMA after application of $100 \%$ eucalyptol for $10 \mathrm{~min}$ was noted when compared with the control group (15.5-12.42 MPa). The percentage of shear strength reduction in this study was different from that reported previously where approximately $36 \%$ decrease in shear strength was observed after $10 \mathrm{~min}$ of eucalyptus oil application (13.81-8.88 MPa) [16]. Although the previous study did not mention the type of eucalyptus oil used, they explicitly elaborated that the preparation contained $75-80 \%$ eucalyptol. Nevertheless, the difference in the proportion of shear strength reduction between the two studies might be due to differences in the type of adhesive used [17]. After polymerization, the bis-GMA resins form a three-dimensional network combined with fillers, which result in the formation of a strong mechanical structure. In contrast, 4-META/MMA-TBB resin assumes a linear morphology with no filler after polymerization [18]. Absorption of solvents is directly related to the degree of crosslinking. Therefore, the slightly cross-linked polymer becomes more sensitive to the plasticizing reaction [19]. This indicates that the 4-META/ MMA-TBB adhesive resin was easier to debond when compared with the bis-GMA adhesive resin.

The optimal shear bond strength for orthodontic brackets to withstand the forces of mastication is 5.9-7.8 MPa [20]. The shear strength of the material in Group 2 (12.42 $\mathrm{MPa}$ ) was greater than the optimal shear bond strength. Williams and Bishara were the first who examined the amount threshold of force that a patient could tolerate during debonding [21]. The force threshold is influenced by the direction of the debonding force; intrusion forces with a threshold force of up to 934 gf were better tolerated, whereas extrusion forces were less tolerable with the threshold decreasing to 827 gf [21]. The shear strength in Group 2 (12.46 MPa, equivalent to 13480 gf) was much higher than the tolerance threshold value. Hence, the application of eucalyptol for 10 min may not be sufficient to decrease the shear bond strength of the resin and eliminate the pain experienced by the patient during debonding.

The specimens in the current study were smeared with eucalyptol 3 times every $3 \mathrm{~min}$ for a total of $10 \mathrm{~min}$. This indicates that $100 \%$ eucalyptol application for longer periods could lead to the softening and 
dissolution of the adhesive resin. However, further studies determining the depth of penetration of eucalyptol into the adhesive material are merited.

\section{CONCLUSION}

The lowest shear bond strength was observed in Group 2 before the debonding procedure, followed by Groups 1 (75\% eucalyptus oil) and 3 (aquades), indicating that $100 \%$ eucalyptol was more effective in decreasing the shear bond strength of bis-GMA adhesive resin when compared with eucalyptus oil. However, the shear bond strength after 10 min of $100 \%$ eucalyptol application remained within the clinically acceptable range. Thus, the $10 \mathrm{~min}$ application period might not be sufficient to decrease the shear bond strength and effectively eliminate the pain involved during the debonding procedure. Further studies are required to evaluate the depth of penetration of eucalyptol into the adhesive material and the amount of pain experienced by patients during the debonding of orthodontic brackets.

\section{ACKNOWLEDGMENT}

The authors are grateful to drg. Krisnawati, Sp.Ort(K), Dr. drg. Miesje K. Purwanegara, SU, Sp.Ort(K), and drg. Benny M. Soegiharto, M.Sc, MOrthRCS, Ph.D, Sp.Ort for critically reviewing the study; drg.Siti Triaminingsih, MT for technical advice; Mas Dudi as the technical support; and all the staff at the Department of Orthodontics, Faculty of Dentistry, University of Indonesia, for their kind help and support throughout this study.

\section{CONFLICTS OF INTEREST}

The authors have nothing to disclose.

\section{REFERENCES}

1. Pithon MM, Santos Fonseca Figueiredo D, Oliveira DD, Coqueiro Rda S. What is the best method for debonding metallic brackets from the patient's perspective? Prog Orthod 2015;16:17.

2. Jena AK, Duggal R, Mehrotra AK. Physical properties and clinical characteristics of ceramic brackets: A comprehensive review. Trends Biomater Artif Organs 2007;20:1-17.

3. Hellak A, Ebeling J, Schauseil M, Stein S, Roggendorf M, Korbmacher-Steiner $\mathrm{H}$, et al. Shear bond strength of three orthodontic bonding systems on enamel and restorative materials. Biomed Res Int 2016;2016:6307107.

4. Kailasam V, Valiathan A, Rao N. Histological evaluation after electrothermal debonding of ceramic brackets. Indian J Dent Res 2014:25:143-6.

5. Alakus Sabuncuoglu F, Ersahan S, Erturk E. Debonding of ceramic brackets by Er: YAG laser. J Istanb Univ Fac Dent 2016;50:24-30.

6. Alessandri Bonetti G, Incerti Parenti S, Ippolito DR, Gatto MR, Luigi C. Effects of ultrasonic instrumentation with different scalertip angulations on the shear bond strength and bond failure mode of metallic orthodontic brackets. Korean J Orthod 2014;44:44-9.

7. Santana RM, Rached RN, Souza EM, Guariza-Filho O, Camargo ES, Pithon MM, et al. Effect of organic solvents and ultrasound on the removal of orthodontic brackets. Orthod Craniofac Res 2016;19:137-44.

8. Yu CC, Yu JH, Lin HJ. An investigation of the effects of chemical reagents on the shear bonding forces of orthodontic metal brackets. Dentistry 2016;6:380.

9. Biazuz J, Zardo P, Junior SA. Water sorption, solubility and surface roughness of resin surface sealants. Braz J Oral Sci 2015;14:27-30.

10. Bonsor SJ, Pearson GJ. A Clinical Guide to Applied Dental Materials. China: Elsevier; 2013

11. Münchow EA, Ferreira AC, Machado RM, Ramos TS, Rodrigues-Junior SA, Zanchi CH, et al. Effect of acidic solutions on the surface degradation of a micro-hybrid composite resin. Braz Dent J 2014; 25:321-6.

12. Park ES, Kim CK, Bae JH, Cho BH. The effect of the strength and wetting characteristics of bis-GMA/TEGDMA-based adhesives on the bond strength to dentin. J Kor Acad Cons Dent 2011;36:139-48.

13. Barton AF, Knight AR. Determination of cohesion parameters for terpenoids such as 1,8-cineole using semi-empirical methods and calculationsbasedongroupcontributions. JChemSocFaradayTrans 1996; 92:753-55.

14. Arnita P. Effect of Variance and Density of Eucalyptus Leaves (Melaleuca leucadendron Linn.) in a Kettle on the Yield and Quality of Eucalyptus Oil. Bogor: Institut Pertanian Bogor; 2011.

15. ChouBA,KoenigJL.Areviewofpolymerdissolution.ProgPolymSci2003; 28:1223-70.

16. Yu CC, Yu JH, Wu CS. Effect of the gel form of eucalyptol on the shear bonding forces of orthodontic brackets. J Dent Sc 2014;9:388-93.

17. Anusavice KJ, Shen C, Rawls HR. Phillips' Science of Dental Materials. $12^{\text {th }}$ ed. China: Elsevier Saunders; 2013.

18. Masuhara E, Nakabayashi N. Products and Practical Information Dental Adhesive Resin Cement Superbond C and B. Japan: Sun Medical Co.

19. Moraes RR, Schneider LF, Sobrinho LC, Consanic S, Sinhoreti MA. Influence of ethanol concentration on softening test for cross-link density evaluation of dental composites. Mat Res 2007;10:79-81.

20. Reynolds IR. A review of direct orthodontic bonding. Br J Orthod 1975; 2:171-8.

21. Mangnall LA. A Randomised Controlled Trial to Assess the Pain Associated with the Debond of Orthodontic Fixed Appliances. Birmingham: University of Birmingham; 2011. 